\title{
Joubert's Syndrome: A Case Report
}

\author{
Amin $\mathrm{A}^{1}$, Farooq $\mathrm{A}^{2}$, Ali M Lone ${ }^{3}$, Irfan $\mathrm{H}^{4}$, Wani $\mathrm{S}^{5}$, Hamid $\mathrm{R}^{6}$ \\ ${ }^{1}$ Dr. Abid Amin, MBBS, Senior Resident in Paediatrics, Sher-i-kashmir Institute of Medical Sciences and Medical \\ College Hospital Bemina, ${ }^{2}$ Dr. Arshad Farooq, MBBS, MD, Professor in Paediatrics, Sher-i-kashmir Institute of Medical \\ Sciences and Medical College Hospital Bemina, ${ }^{3}$ Dr. Ali M Lone Resident in Surgery, Sher-i-kashmir Institute of Medical \\ Sciences Soura, ${ }^{4}$ Dr. Hakim Irfan, MBBS, Resident in Paediatrics, Sher-i-kashmir Institute of Medical Sciences and \\ Medical College Hospital Bemina, ${ }^{5}$ Dr. Shayiq Wani, MBBS, Resident in Paediatrics, Sher-i-kashmir Institute of Medical \\ Sciences and Medical College Hospital Bemina, ${ }^{6}$ Dr. Raashid Hamid Resident in Surgery, Sher-i-kashmir Institute of \\ Medical Sciences Soura.
}

Address for correspondence: Dr. Abid Amin, E-mail: abid.amin4@gmail.com

\begin{abstract}
Joubert's syndrome is an autosomal recessive congenital disorder having characteristic clinical features like hypotonia, ataxia, developmental delay and many neurological problems. Other variable features include retinal dystrophy, cystic kidney disease liver fibrosis etc. Treatment for Joubert syndrome is symptomatic and supportive. Infant stimulation and physical, occupational, and speech therapy may benefit some patients. Infants with abnormal breathing patterns should be monitored.
\end{abstract}

Key words: Joubert's syndrome, molar tooth sign, cerebellar peduncles, vermis hypoplasia.

\section{Introduction}

Joubert's syndrome is a rare Autosomal recessive disorder, characterized by a specific congenital malformation of hindbrain and a broad spectrum of other phenotypic findings such as intellectual disability, hypotonia,and often, abnormal respiratory pattern and/ or abnormal eye movements ${ }^{1}$. Joubert et al (1969) described four French Sibs with most cases of Joubert's syndrome being sporadic. The prognosis of individuals with Joubert's syndrome varies. Some patients have a mild form with minimal motor disability and good mental development while others may have severe motor disability with moderate mental retardation ${ }^{2}$.

\section{Case History}

A two years old male baby was brought by his mother presented with a history of episodic breathlessness and developmental delay. He was the first issue born of second degree consanguineous marriage with a normal vaginal delivery and cried immediately at birth. He had been admitted to hospital for some respiratory problem but the records were not available. The family history was non contributory.
On clinical examination he had gross developmental delay in motor milestones in the form of not being able to walk and even stand but, he was able to hold his head and roll over i.e. a developmental motor age of 6 months. He was able to speak bisylables only. His weight was 7 $\mathrm{Kgs}$ (3rd percentile NCHS). His length was $88 \mathrm{~cm}\left(50^{\text {th }}\right.$ percentile NCHS). Head circumference was $48 \mathrm{~cm}\left(50^{\text {th }}\right.$ percentile NCHS). Chest circumference was $47 \mathrm{~cm}$, upper segment lower segment ratio was 1.6 (normal for age). Abdominal circumference was $43 \mathrm{~cm}$ and midarm circumference was $13 \mathrm{~cm}$.

Pulse rate was 98 beats per minute regular with good volume and no radio femoral or radio carotid delay. Blood pressure was $80 / 60 \mathrm{mmHg}$ (normal for age). Temperature was $100^{\circ} \mathrm{F}$. The patient had episodes of Hyperpnea followed by apnea in the hospital during which period the Respiratory examination was normal other than increased rate, The cardiac examination was also normal. This Pointed towards a central cause of his respiratory problem. He also had bilateral horizontal nystygmus. Chest examination was normal and CVS showed normal heart sounds. Neurological examination showed hypotonia, sluggish deep tendon 
reflexes. The Child also had a mirror play sign wherein both limbs move simultaneously. Echocardiography and Ultrasound of the abdomen was normal. Then MRI brain was done which showed," molar tooth sign". Based on these clinical features and neuroimaging, a diagnosis of Joubert's syndrome was made.

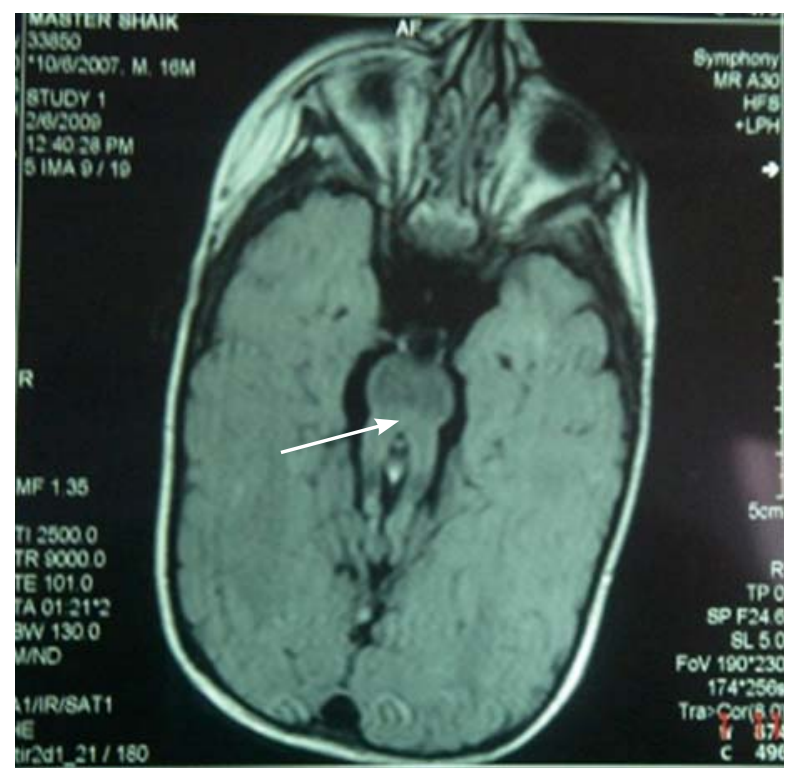

Fig 1: MRI of Brain Showing Molar Tooth Sign (White Arrowhead)

\section{Discussion}

Joubert's syndrome (JS) is an autosomal recessive disorder characterized by hypotonia, poor body balance, developmental delay, respiratory abnormalities characterized by tachypnea followed by apnea ${ }^{3}$.This syndrome was first described by Joubert and colleagues as a familial agenesis of the cerebellar vermis and appeared to be inherited as an Autosomal Recessive trait.

Joubert's syndrome related disorders (JSRD) are included in the rapidly expanding group of disorders called Ciliopathies because all six gene products implicated in JSRD (NPHP1, AHI1, CEP290, RPGRIP1L, TMEM611 and ARL13B) function in primary cilium/basal body organelle $3,4,5$.
The AHI1 whose mutation is thought to be responsible for JS in many families and it codes for a protein that is strongly expressed in the brain and appear to play an important role in development especially in brain wiring. Many nerve fibres in children with JS don't cross the midline of the brain as they would do in normal development.This problem leads to abnormal, "Mirror Play" in which both limbs move simultaneously.

JS affect 1 in 100000 children approximately i.e. 40 babies per year in US ${ }^{4,5}$. Neuroimaging of head in the axial plane demonstrate the, Molar Tooth Sign"-deep posterior interpeduncullar fossa, thick and elongated superior cerebellar peduncles and hypoplasia or aplasia of vermis ${ }^{6}$. The CNS malformation spectrum and neuropathic studies accounts for many clinical features of joubert's syndrome.

\section{References}

1. Brancati F, Dallapiccola B, Valente EM.Joubert Syndrome and related disorders. Orphanet J Rare Dis. 2010;8:5:20.

2. Saraiva JM, Baraitser M. Joubert syndrome: a review. Am J Med Genet 1992;43:726-31

3. Braddock SR, Henley KM, Maria BL. The face of Joubert syndrome: a study of dysmorphology and anthropometry. Am J Med Genet 2007;143:323542.

4. Parisi MA, Doherty D, Eckert ML, Shaw DW, Ozyurek $\mathrm{H}$, Aysun $\mathrm{S}$ et al. AHI1 mutations cause both retinal dystrophy and renal cystic disease in Joubert syndrome. J Med Genet 2006;43:334-39.

5. Gleeson JG, Keeler LC, Parisi MA, Marsh SE, Chance PF, Glass IA, et al. Molar tooth sign of the midbrain-hindbrain junction: occurence in multiple distinct syndromes. Am J Med Genet 2004;125:12534.

6. Maria $\mathrm{BL}$, Hoang $\mathrm{KB}$, Tusa RJ, Mancuso $\mathrm{AA}$, Hamed LM, Quisling RG et al. "Joubert syndrome" revisited: key ocular motor signs with magnetic resonance imaging correlation. J Child Neurol 1997;12:423-30.

\section{How to cite this article?}

Amin A, Farooq A, Ali M Lone, Irfan H, Wani S, Hamid R. Joubert's Syndrome: A Case Report. J Nep Paedtr Soc 2011;31(2):141-142. 